\title{
PODCAST
}

\section{First Rounders: Katrine Bosley}

Katrine Bosley is former CEO of Editas Medicines and Avila Therapeutics. She discusses growing up in Ohio, her first job in biotech (as an administrative assistant), and why her 5 years at Editas felt more like 1,000 .

https://aca.st/3e5a7f

Published online: 8 July 2020

https://doi.org/10.1038/s41587-020-0598-9

\section{RESEARCH HIGHLIGHTS}

\section{Papers from the literature}

Selected by the Nature Biotechnology editors.

An in vitro model of early anteroposterior organization during human development

Moris, N. et al. Nature https://doi.org/10.1038/s41586-020-2383-9 (2020).

Targeted Perturb-seq enables genome-scale genetic screens in single cells

Schraivogel, D. et al. Nat. Methods https://doi.org/10.1038/s41592-020-0837-5 (2020).

Personalized mapping of drug metabolism by the human gut microbiome Javdan, B. et al. Cell https://doi.org/10.1016/j.cell.2020.05.001 (2020).

Multilayered VBC score predicts sgRNAs that efficiently generate loss-of-function alleles

Michlits, G. et al. Nat. Methods https://doi.org/10.1038/s41592-020-0850-8 (2020).

Hair-bearing human skin generated entirely from pluripotent stem cells

Lee, J. et al. Nature https://doi.org/10.1038/s41586-020-2352-3 (2020). 